\title{
CYBERBULLYING PREVENTION AND INTERVENTION PROGRAMS - ARE THEY ENOUGH TO REDUCE THE NUMBER OF THE ACTS OF ONLINE AGGRESSION?
}

\author{
ELENA-ANCUȚA ZĀVOIANU \\ University of Bucharest \\ Faculty of Psychology and Educational Sciences \\ Bucharest, Romania \\ E-mail address: elena.zavoianu@drd.unibuc.ro \\ ORCID: https://orcid.org/ 0000-0001-6284-6181 \\ ION-OVIDIU PÂNIȘOARÃ \\ University of Bucharest \\ Faculty of Psychology and Educational Sciences \\ Bucharest, Romania \\ E-mail address: ovidiu.panisoara@fpse.unibuc.ro \\ ORCID: https://orcid.org/0000-0002-7073-3248
}

\begin{abstract}
Aim. Cyberbullying has become a global problem that affects millions of teenagers, causing depression, anxiety, decrease in school performance, and even dropping out of school, substance abuse or suicide. It is manifested through frequent aggressions online, with the sole purpose of causing suffering. Due to its constantly growing occurrence, cyberbullying has become a concern for psychologists, sociologists, and teachers. The existing body of research emphasizes the importance of identifying the groups that are prone to be victims of online harassment; the effect that it has on its victims; the prevention methods; and the counseling for the victims. Many countries have created prevention and intervention programs for cyberbullying to solve the cases of online aggression. However, sometimes these prevention and intervention programs are not enough to solve the cyberbullying conflicts and reduce the number of cases.

Methods. In order to provide a complete picture of this phenomenon, we analyzed some news and testimonies from Romania regarding the cases of cyberbullying and some methods of prevention of and intervention in cyberbullying that Romania and other countries have adopted. Having studied the materials and the programs implemented in other countries, we conducted a research with 108 psychologists from Romania to find out what is their opinion about the discrepancy of the cases reported to the authorities and the real ones, but as well as about the programs developed.
\end{abstract}


Results. The results of this research study show that the intervention and prevention programs that have been adopted are essential in the reduction of cyberbullying cases, but these programs have to be combined with personalised intervention that can be made online.

Key words: cyberbullying, victim, aggressor, internet, intervention, counseling, prevention

\section{INTRODUCTION}

Tn a constantly reforming and innovating society, such as that of the 21st century, Ithe communication and learning processes extend into the online environment, gaining more and more territory. At the same time, phenomenona such as "cyberbullying" or the so-called harassment/online aggression, are gradually developing therein as well. The existence and ongoing development of social network applications, such as Facebook, Instagram, Whatsapp, Skype, Twitter, Tik Tok, Zoom, Snapchat etc., allow people to stay connected with family, friends and teachers, simultaneously exposing them as potential victims of online aggression.

Cyberbullying can be considered an extension of the bullying phenomenon, which includes the use of technology and the Internet (Smith et al., 2008). Bullying is an aggressive and antisocial behavior exercised intentionally and repeatedly by one or more aggressors on a victim, between whom there is an unequal power relationship (Rigby, 2003). It can take three forms: physical, verbal and social. According to Vaillancourt et al. (2017), the phenomenon of bullying is very present in school, while cyberbullying is present at home.

The bullying and cyberbullying concepts are similar regardind their three main characteristics: intentionality, frequency and unequal power relations (Tokunaga, 2010), whereas they can be distinguished by the anonymous character of cyberbullying. In most cases, the aggressor carries out such activities consciously and repeatedly in order to harm the victim, for whom she/ he does not feel empathy. The victim is usually weaker than the aggressor and defenseless.

Subjecting the victim to such aggression can lead to decreased self-esteem, cancellation of future plans, installation of anxiety, depression, and even abuse of prohibited substances, sleep disorders, decreased school performance, absenteeism and even school dropout, in extreme cases ending with crime or suicide (Privitera, \& Campbell, 2009). The age group most exposed to this phenomenon is represented by teenagers between the ages of 11 and 16 (Kowalski, Limber, \& Agatston, 2007). A research conducted by the psychologists Boca-Zamfir and Tiuliuc (2018) highlighted that in Romania cyberbullying cases are influenced by the time spent on the Internet, with boys spending more time online. However, the negative effects, such as depression, anxiety, low self-esteem, are more pronounced in girls than in boys.

Smith et al. (2007) classify the ways in which victims can be harassed online: messages, phone calls, emails, comments, blogs, image posts and videos that lead to the victim's denigration. This can be manifested through: disputes, 
harassment, denigration, creating false profiles, deception, exclusion and online prosecution (Willard, 2007).

The number of cyberbullying cases is increasing due to the fact that an aggressor can intimidate their victim whenever she/he wants, while maintaining her/his anonymous identity (Wright, 2014). Although the victim can log out of the respective sites or deactivate their accounts, the content posted publicly by the aggressor, remains there and can be viewed by a lot of people. The ability to remain anonymous or create false identities causes teens to be more uninhibited and to say or do things they would not do in real life with the same ease, increasing their chances of being attacked online (Suler, 2004).

Victims of physical aggression are often victims of online aggression. Thus, the harassment of the victim is continuous.

Those involved directly or indirectly in online aggression are considered witnesses or accomplices. Depending on how they act, they can play one of the following roles: assistants of the aggressor (directly involved), supporters of the aggressor (those who strengthen and encourage the behavior), neutral witnesses (who look passively) and supporters of the victim (who insure victim support). According to Hawkins et al. (2001), involving witnesses in helping victims would provide negative feedback to the aggressor, and bullying episodes would decrease. Unfortunately, more and more witnesses remain passive, unaware of the importance of their impact (Pöyhönen et al., 2010). Most of the time, they perceive cyberbullying as a joke, which is why they distribute inappropriate content on their pages or profiles (Kowalski, 2008).

Currently, cyberbullying is a problem debated by many specialists in the field of psychology, sociology and education. Given the ongoing evolution of technology and online media, cyberbullying has no clearly defined boundaries, being difficult to identify and interpret by victims and witnesses. Due to the lack of information and defined boundaries, people may not be aware that they are or were victims of cyberbullying.

Establishing clear boundaries and adjusting to the cultural context can facilitate the identification of cyberbullying cases and especially the involvement of witnesses in helping victims and even denouncing the aggressors.

\section{THE ROMANIAN CONTEXT}

In Romania, cyberbullying is not a very well defined phenomenon. Therefore, it is difficult to identify the frequency of cyberbullying cases and the number of complaints to the police is quite small compared to other countries. In order to identify how this phenomenon occurs in our country, we analyzed a number of 27 newspapers, news, and testimonies on cyberbullying from both online and offline environment.

The selected materials had to fulfil the following criteria: 
a) they had to describe cyberbullying cases from Romania;

b) they had to include at least one minor;

c) they had to be published no later than in 2008 .

The selection process was quite complicated, since most of the victims were minors who could not be exposed and most of the cases were presented by their parents. The majority of the materials present on the social media described only a very few and grave cases. Despite this fact, many studies among children conducted in Romania revealed that in fact 5 out of 10 children have experienced cyberbullying (Grădinaru \& Stoica, 2018).

Following the analysis, we discovered that a significant number of reported cyberbullying cases occur in the urban area. The number of cases of cyberbullying in the rural area is smaller than in the urban area, either due to the lack of access to the Internet or technology, the domestic activities the children carry out, or their moral and cultural values. It is also possible that these cases are not made public.

The cyberbullying cases that were described in the studied sources were: sending offensive messages or content, threatening, sexting and sexual harassment or porn revenge. Using pictures and videos in the process of cyberbullying has a higher negative impact on the victims than the other types of cyberbullying (Slonje \& Smith, 2008).

The analyzed sources indicate that the platforms on which these cases took place most often are Facebook and Instagram. In a study conducted by Grădinaru and Stoica (2018), 99.3\% of the children said they have one profile on a social network, and the most popular social networks among the children are Facebook (95.9\%), YouTube (90.5\%) and Instagram $(81.4 \%)$.

In most of the cyberbullying cases presented in various online and offline sources, the victims are girls. This is also supported by a research conducted by the Association Save the Children Romania (2018), according to which 54\% of children were victims of online aggression, the percentage being significantly higher among girls and high school students. Girls are usually harassed through instant messaging, while boys are harassed on online groups, forums and in various games.

In order to decrease the number of cases of cyberbullying in Romania, the program "Net hour" has been developed since 2008. This program organized training activities and developed educational resources for parents, teachers and specialists, as well as offered advice and a reporting line for the victims. Despite that, the cases of cyberbullying have registered an upward trend over the years, and according to K. Athanasiou's (2018) research, Romania has one of the highest rates of cyberbullying cases in Europe (37.3\%). Romania is followed by Greece (26.8\%), Germany $(24.3 \%)$ and Poland $(21.5 \%)$, while at the opposite pole with the lowest rate there is Spain (13.3\%).

In all countries presented in K. Athanasiou's study, digital literacy programs have been developed for students, teachers and even parents, such as TABBY, TEI, MEDIA HEROUS, Agurate etc. All the countries have one or more programs that fight against bullying and cyberbullying, but we chose 
only those that we considered representative for each country. All these programs are aimed to reduce the cases of bullying that occur both in the school environment and outside in the online environment, by offering information seminars about the effects of cyberbullying, encouraging witnesses to provide help, encouraging victims to ask for help, creating a positive school climate, increasing the level of well-being, increasing empathy, social responsibility and reducing the level of tolerance towards aggression.

Although all these countries have implemented programs to combat this phenomenon, the number of cases does not seem to decrease. In the actual context of today, when COVID-19 has forced some European teachers to move their teaching process online, it is challenging to continue carrying out these programs. This is why we would like to argue that these strategies need to be improved and continued online, considering that face-to-face communication is impossible.

In Romania, the aspects such as the familiarization of children with the concepts of bullying and cyberbullying, the effects of these behaviors, and how they have to handle these situations do not encourage the children to ask for the help of their family, teachers, school counselors and even the authorities, which is reflected by the low number of news on this subject, and also in the research conducted by Save the Children Romania (2018), where only 17\% of the children discussed with someone what happened in the online environment, out of whom $69 \%$ with parents, $26.3 \%$ with their sister or brother, $64.5 \%$ with a friend, $19.5 \%$ with a teacher, $25.5 \%$ with a colleague, $8.5 \%$ with someone who deals with the protection of children and only $10.6 \%$ with a specialized counseling line.

Why these children do not tell their parents what they are going through? How can we encourage children to ask for help? How should these intervention and prevention programs be adapted to respond to the needs of children? These are some of the questions we want to answer in our research.

\section{METHODS \& PROCEDURE}

We have designed a qualitative research attempting at answering the aforementiones questions and providing solutions to the posed issues. The applied research method was the questionnaire that was conducted both online and on paper, on the sample of 108 psychologists and school counselors. It contained 15 open and closed questions; the questions were related to personal information and cyberbullying among students.

\section{PARTICIPANTS \& RESULTS}

108 participants took part in this study. The number of men was lower, being represented by a percentage of $21.3 \%$. $73.1 \%$ of the participants were from the urban area. In this research, we involved only participants who had experience in cyberbullying counseling. 
The greatest difficulties encountered by psychologists and school counselors in counseling victims and witnesses of the cyberbullying phenomenon were related to convincing victims to talk about what happened, to declare the aggressor's identity in cases where they were known persons, to regain their self-confidence and reintegrate into the group of friends/school.

According to psychologists, the number of children that are asking for the help of their parents or other competent persons is small because children can consider themselves guilty of being victims of the online aggression; some children consider that they can handle it alone; some are afraid of the parents' reaction, who are often confiscating the mobile device; some experience shame; and some are afraid of the aggressor.

In the opinion of the Romanian psychologists and school counselors, this phenomenon affects over $80 \%$ of the children in Romania, claiming that the number may be higher, but the lack of clear conceptual boundaries makes it difficult to identify the victims. They consider that the number of cases can increase especially now, when most of school courses are being done online because of COVID-19.

Regarding the programs of prevention of cyberbullying that are currently being carried out, the participants thought that the developed programs are complex and sometimes efficient, but they should be mandatory at all the educational units, should be carried out permanently and not for several weeks only, and should be available on the Internet. The programs should further promote the involvement of students in activities by organizing competitions and not just conducting information campaings.

They consider that the most important methods of preventing cyberbullying are the introduction of digital literacy courses in the children's curriculum; the limitation of the time spent on the Internet by parents; and the development of online programs that can detect online aggression on social media platforms.

The intervention in cyberbullying cases consists only of the counseling offered by a psychologist and the support offered by the family. However, this happens quite rarely, and only when a victim confesses what he or she is going through. Currently, children, parents and teachers do not know how to recognize the effects of cyberbullying on the mental and physical state of the victim. The participants consider that the therapeutic intervention of the psychologist should be complemented by the family at home, as well as by the teachers at school.

Regarding the strategies of intervention in the cases of the victims, the following were specified: providing psychological counseling both offline and online, introducing courses of digital literacy for children and building stronger relationship between children and their parents. These methods of intervention involve psychologists who can provide cognitive behavioral therapy, family, who can provide security and unconditional love, and teachers, who can ensure a positive climate at school.

Regarding the intervention in the case of the aggressor, it consisted of cognitive-behavioral psychotherapy both offline and online, and the applica- 
tion of sanctions. It is very important that the counseling of aggressors can be done online. Many aggressors refuse to join counseling programs because they are afraid of being judged and punished. The existence of a platform where an aggressor is not required to reveal his/her true name can greatly facilitate the counseling process and especially reduce the number of victims. Furthermore, in order to limit the cyberbullying cases, the undertaken actions should include not only informing students, parents and teachers about the effects of this phenomenon, treating the victims, but also treating the aggressors and the bystanders.

Each school must develop their policies on cyberbullying, rules for the use of mobile devices and the Internet, as well as consequences for students who do not comply with ethical and legal standards. The responsibilities of teachers in handling such cases, according to psychologists, are organization of informative workshops regarding the effects of cyberbullying; coordination of personal development classes in collaboration with the school counselor; introduction of activities aimed at teamwork, cooperation and tolerance; frequent discussions with parents; establishment of firm and clear rules regarding the use of mobile phones in schools.

According to the specialists, parents of students who are the victims of online aggression should discuss daily with their children how to use social media platforms, spend more time with their children and limit children's access to certain sites and the time spent on the Internet. In this way, children will be informed about the negative effects of the Internet, they will have more confidence in their parents and will ask for their help whenever they will need it.

\section{CONCLUSION}

This research highlights the psychologists' claims that the prevention and intervention cyberbullying programs should be continued, yet should be supplemented with online platforms that offer help. This online platform should also be adapted to each cyberbullying case, taking into consideration the personalities of the victim and the aggressor as well as the causes that triggered this behaviour. Thus, it is necessary to develop and complete the actual intervention strategies that will correspond each case of cyberbullying. We can see the willingness of psychologists to counsel the victims, but also a reluctance of the aggressors.

\section{LIMITATIONS OF THE RESEARCH}

Despite a thorough data collection process, the following difficulties occured: the lack of identification and selection of a large number of participants; the insincerity of some respondents, and incomplete answers to the open items. 


\section{ONLINE INTERVENTION}

As cyberbullying is a type of aggression that occurs in the online environment, we believe that the effective method of intervention would be one that takes place online, namely an online counseling platform for victims, perpetrators, witnesses, parents and all persons involved in such cases.

The victims are inclined not to ask for help because of the fear of reprisal, embarrassment, or conviction that their parents and/or teachers will not help them (Notar et al., 2013). By having such a platform, where they will not have to reveal their true identity, victims may be encouraged to ask for help more often. Adolescents do not want to be considered informers or incapable of coping alone with the situations they face by their friends, and for this reason, they do not ask for help.

The platform would involve hiring psychologists and counselors to fight against cyberbullying. They could provide support through chat, video or phone calls. Adolescents are more open regarding written communication than phone calls. Employees would be available 24 hours a day, answering questions, offering tips and providing online therapy for people in difficulty. Subsequently, counseling sessions could be held face to face, if the victim agreed.

The online platform would provide free services for all the people involved in such cases, ensure anonymity and create intervention plans for each case. The specialists working on platform would also collaborate with the authorities to identify the aggressors, who can also be included in the cognitive-behavioral therapy.

Information programs regarding this phenomenon, the introduction of ICT courses in the school syllabus and the support of literacy workshops for teachers and parents will always be welcomed. But as long as they are carried out at a general level, and not at a particular one- adapted to the needs of each student - they will not produce the expected changes.

Many already-existing online platforms support victims through providing information on how to prevent, identify and manage cyberbullying situations, but these platforms do not interact directly with the person in need.

\section{CONCLUSION AND FUTURE WORK}

The aggressor and the victim represent a social phenomenon that must be tackled and treated together to restore the balance and the harmony in real and virtual life. Immediate action is absolutely necessary in such cases in order to avoid the increase in the number of persons abused online by the same aggressor and consequently transforming them into aggressors. Labeling the victim and the aggressor will not change the situation at all. On the contrary, the aggressor's power will be fuelled, and they will do more harm. Treating only the victim will also not be enough to restrict this phenomenon. Intervention is required on two levels, namely the victim and the aggressor. What is 
more, information campaigns on cyberbullying and activities that contribute to the personal, emotional and relational development of children are essential in mitigating and preventing these aggressions.

In conclusion, cyberbullying can be reduced by developing online and offline programs that may have the following purposes: informing students about cyberbullying and its effects; involving students in educational activities that will increase their empathy, resilience and interpersonal skills; providing online counseling and closer supervision by parents; and building an effective relationship between student - teacher - parent - counselor.

\section{REFERENCES:}

[1] Athanasiou, K., Melegkovits, E., Andrie, E. K., Magoulas, C., Tzavara, C. K., Richardson, C., Greydanus, D., Tsolia, M., \& Tsitsika, A. K. (2018). Cross-national aspects of cyberbullying victimization among 14-17-year-olds adolescents across seven European countries. BMC Public Health, 18, 800.

[2] Boca-Zamfir, M., \& Turliuc, M. N., (2018). Cyberbullying among Romanian adolescents: the relationships between the cyberbullying status and depression, anxiety, and self -esteem. The Fifth International Conference on Adult Education - Education for values - continuity and context, Proceedings of CIEA, 375-382;

[3] Notar, C. E., Padgett, S., \& Roden, J. (2013). Cyberbullying: Resources for intervention and prevention. Universal Journal of Educational Research, 1, 133-145.

[4] Del Rey, R., Ortega-Ruiz, R., \& Casas, J. A. (2019). Asegúrate: An intervention program against cyberbullying based on teachers' commitment and on design of its instructional materials. International Journal of Environmental Research and Public Health, 16, 434.

[5] DeSmet, A., Aelterman, N., Bastiaensens, S., Van Cleemput, K., Poels, K., Vandebosch, H., Cardon, G., et al. (2015). Secondary school educators' perceptions and practices in handling cyberbullying among adolescents: a cluster analysis. COMPUTERS \& EDUCATION, 88, 192-201.

[6] Giménez-Gualdo, A., Pilar-Arnaiz, S., Fuensanta-Cerezo, \& Prodócimo, E. (2018). Teachers' and students' perception about cyberbullying. Intervention strategies in Primary and Secondary education. Comunicar, 56, 29-38.

[7] Hawkins, D. L., Pepler, D. J., \& Craig, W. M. (2001). Naturalistic observations of peer interventions in bullying. Social Development, 10, 512-527.

[8] Kowalski, R. M. (2008). Cyber bullying: Recognizing and treating victim and aggressor. Psychiatric Times, 25, 1-2.

[9] Kowalski, R., \& Limber, S. (2007). Electronic bullying among middle school students. Journal of Adolescent Health ,41, S22-S30.

[10] Pöyhönen, V., Juvonen, J., \& Salmivalli, C. (2010). What does it take to stand up for the victim of bullying? The interplay between personal and social factors. Merrill-Palmer Quarterly, 56 (2), 143-163.

[11] Privitera, C., \& Campbell, M. (2009). Cyberbullying: The new face of workplace bullying? CyberPsychology \& Behavior, 12, 395-400.

[12] Rigby, K. (2003). Why do some children bully at school? School Psychology International, 26 (2), $147-161$.

[13] Smith, K., Mahdavi, J., Carvalho, M., Fisher, S., Russell, S., \& Tippett, N.(2008). Cyberbullying: its nature and impact in secondary school pupils. The Journal of Child Psychology and Psychiatry, 49 (4), 376-385.

[14] Suler, J. (2004). The online disinhibition effect. CyberPsychology \& Behavior, 7, 321-326.

[15] Tokunaga, R. S. (2010). Following you home from school: A critical review and synthesis of research on cyberbullying. Computers in Human Behavior, 26, 277-287.

[16] Vaillancourt, T., Faris, R., \& Mishna, F. (2017). Cyberbullying in children and youth: implications for health and clinical practice. The Canadian Journal of Psychiatry, 62 (6), 368-373. 
[17] Van Cleemput K., DeSmet, A., \& Vandebosch, H. (2014). A systematic review of studies evaluating anti-cyberbullying programs. Paper presented at Etmaal van Communicatiewetenschap; 3-4 February 2014; Wageningen, Netherlands.

[18] Willard, N. E. (2007). Cyberbullying and cyberthreats: Responding to the challenge of online social aggression, threats, and distress. Champaign, IL: Research Pres.

[19] Williford, A., Boulton, A. J, \& Jenson, J. M. (2014). Transitions between subclasses of bullying and victimization when entering middle school. Aggressive Behavior, 40, 24-41.

[20] Wölfer, R., Schultze-Krumbholz, A., Zagorscak, P., Jäkel, A., Göbel, K., \& Scheithauer, H. (2013). Prevention 2.0: Targeting Cyberbullying @ School. Prevention Science, 1-9.

[21] Wright, M. F. (2014). Cyber victimization and perceived stress: Linkages to late adolescents' cyber aggression and psychological functioning. Youth $\mathcal{E}$ Society, 47, 789-810.

[22] Grădinaru, C., \& Stoica, T. (2018). Study about the use of the Internet among children. Retrieved from https://oradenet.salvaticopiii.ro/docs/Studiu-privind-utilizarea-internetului-decatre-copii-v2-online.pdf

[23] Slonje, R., \& Smith, P. K. (2008). Cyberbullying: another main type of bullying? Scandinavian Journal of Psychology, 49, 147-154. 